\title{
SÚMULA 611 DO SUPERIOR TRIBUNAL DE JUSTIÇA: ATIVISMO JUDICIAL E O RISCO À INVIOLABILIDADE DA INTIMIDADE, DA VIDA PRIVADA, DA HONRA E DA IMAGEM DAS PESSOAS
}

\author{
SUMMARY 611 OF THE SUPERIOR COURT OF JUSTICE: JUDICIAL ACTIVISM AND \\ THE RISK TO INVIOLABILITY OF PRIVACY, PRIVATE LIFE, HONOR AND THE \\ IMAGE OF PEOPLE
}

Ewerton Ricardo Messias

Doutorando em Direito pela Universidade de Marília. Mestre em Direito pela Universidade de Marília. Especialista em Direito e Gestão Ambiental pela Faculdade de Ciências Jurídicas e Gerenciais de Garça. Professor nos cursos de Graduação em Direito e Administração na Universidade de Marília.

Valter Moura do Carmo

Doutorado em Direito pela UFSC. Mestre em Direito Constitucional pela UNIFOR. Diretor de relações institucionais do CONPEDI. Professor Assistente Doutorado da UNIMAR, onde leciona nos cursos de graduação em Direito e Medicina, sendo professor permanente do Programa de Pós-Graduação em Direito.

\section{Resumo}

O presente artigo objetiva analisar a influência da principiologia pósmoderna sobre os conceitos jurídicos indeterminados e o ativismo judicial, a fim de verificar a constitucionalidade da Súmula 611 do Superior Tribunal de Justiça (STJ) no âmbito do Estado Democrático de Direito. Com esse intuito, são investigadas a principiologia jurídica pós-moderna e sua influência no surgimento do ativismo judicial; a definição de judicialização e a distinção entre ativismo judicial, livre convencimento motivado do juiz e pró-atividade judicial; e a definição e a inserção dos conceitos jurídicos indeterminados prudência e discrição na Súmula 611 do STJ como forma de afastar sua eventual inconstitucionalidade. A pesquisa justifica-se no fato de que a hermenêutica jurídica pós-moderna possui características específicas, vez que, diante dos conceitos jurídicos indeterminados, exige do operador do Direito uma postura altamente construtiva do conteúdo semântico dos enunciados prescritivos, ambiente fértil para o surgimento do ativismo judicial. Para a obtenção dos resultados almejados pela pesquisa, o método de abordagem seguido será o empírico-dialético, utilizando-se de pesquisa bibliográfica, legislativa e jurisprudencial, tendo como pano de fundo um sistema de referência 
pautado no giro linguístico, representado por meio do Constructivismo Lógico-Semântico de Paulo de Barros Carvalho. Em conclusão, aponta-se que a Súmula 611 do STJ, enquanto desprovida da inclusão da prudência e da discrição na realização das investigações preliminares, revela-se inconstitucional.

Palavras-chave: Pós-modernidade. Conceitos jurídicos indeterminados. Ativismo judicial. Súmula 611 do STJ. Inconstitucionalidade.

\begin{abstract}
This article aims to analyze the influence of postmodern principiology on indeterminate legal concepts and judicial activism in order to verify the constitutionality of Precedent 611 of the Superior Court of Justice (STJ) within the framework of the Democratic State of Law.For this purpose, postmodern legal principles and their influence on the emergence of judicial activism are investigated; the definition of judicialization and the distinction between judicial activism, free convincing conviction of the judge and pro-judicial activity; and the definition and insertion of the legal concepts indeterminate prudence and discretion in the Precedent 611 of the STJ as a way to remove its eventual unconstitutionality. The research is justified in the fact that the postmodern legal hermeneutics has specific characteristics, since, before the indeterminate juridical concepts, it demands of the operator of the Law a highly constructive position of the semantic content of the prescriptive statements, fertile environment for the emergence of the judicial activism. In order to obtain the results sought by the research, the method of approach followed will be the empirical-dialectic, using bibliographical, legislative and jurisprudential research, having as background a reference system based on the linguistic turn represented by Paulo de Barros Carvalho's Constructivism LogicalSemantic. In conclusion, it is pointed out that the STJ's Summary 611, while devoid of the inclusion of prudence and discretion in carrying out the preliminary investigations, is unconstitutional.
\end{abstract}

Key-words: Postmodernity. Undetermined legal concepts. Judicial activism. STJ's Summary 611. Unconstitutionality.

\title{
1. INTRODUÇÃO
}

Após a Revolução Industrial a história do pensamento jurídico passa por um intenso período de mudanças, principalmente a partir da segunda metade do século XX. Tal período, denominado como pós-modernidade, é caracterizado pela socialização e pela constitucionalização do Direito, assumindo, a principiologia constitucional, o lugar antes ocupado pelo positivismo jurídico, representado pelas 
codificações. Sob a justificativa da garantia dos direitos fundamentais e da consolidação da democracia, os princípios jurídicos passam a possuir força normativa, o que causa o início de um efusivo debate acerca da dogmática jurídica e da técnica legislativa utilizada na construção dos enunciados jurídicos prescritivos, os quais tomam como objeto a realidade social (CARVALHO A., 2009, p.575).

Surge, então, no sistema jurídico, um ambiente propício ao surgimento de axiomas e de enunciados jurídicos, estes últimos, revestidos da natureza de princípios, cuja elaboração se dá por meio da utilização da técnica legislativa dos conceitos indeterminados, sendo, desta forma, construídos com uso de termos que se ajustam a inúmeros significados, portanto, carentes de um preenchimento valorativo. Os conceitos jurídicos indeterminados criam uma grande dificuldade para os órgãos aplicadores do direito, principalmente para o Poder Judiciário, pois impossibilita a emissão de decisões a partir da simples subsunção de um fato da vida a uma premissa legal prevista no direito positivo. Tal realidade exige que o juiz passe a adotar uma postura mais qualificada na construção do conteúdo semântico dos enunciados prescritivos sob sua análise, não podendo sua decisão, portanto, ser uma mera declaração individual (subjetiva) de subsunção do fato da vida à norma jurídica positivada.

Nesse panorama, surge a figura do ativismo judicial, sendo, neste ambiente, formulada a Súmula 611 do Superior Tribunal de Justiça (STJ), surgindo com ela dúvidas acerca da inobservância aos princípios da cidadania e da dignidade da pessoa humana, fundamentos da República Federativa do Brasil, bem como dos direitos fundamentais da vedação ao anonimato e da inviolabilidade da intimidade, da vida privada, da honra e da imagem das pessoas, diante da interpretação sistemática do contido no Art. $1^{\circ}$, incisos I e II c.c. o Art. $5^{\circ}$, incisos IV e X, todos da Constituição Federal de 1988 (BRASIL, 1988).

A justificativa para a pesquisa do tema em tela é a recente edição da Súmula 611 do STJ e a necessidade de discussão acerca da existência de ativismo judicial na sua elaboração e de sua inconstitucionalidade por não delimitar os limites de razoabilidade e de proporcionalidade para a relativização dos fundamentos da cidadania e da dignidade da pessoa humana, bem como dos direitos fundamentais da vedação ao anonimato e da inviolabilidade da intimidade, da vida privada, da honra e da imagem das pessoas, diante do tensionamento existente entre eles e o axioma da supremacia do interesse público (LIMA, 2009, p. 132-133). 
Quanto ao objetivo a ser alcançado, trata-se de uma tentativa de clarificar uma eventual situação de inconstitucionalidade da Súmula 611 do STJ, em virtude da prática de ativismo judicial, consistente na não observância da razoabilidade e da proporcionalidade necessárias para a relativização de fundamentos da República Federativa do Brasil e de direitos fundamentais diante do tensionamento existente entre eles e o axioma da supremacia do interesse público.

A despeito da suma importância da matéria abordada, o tema ainda é bastante recente e, portanto, ainda carece de pesquisa aprofundada sob o prisma que ora se pretende focar, lacuna esta que, ao ser preenchida, certamente trará auxílio doutrinário ao intérprete e ao aplicador do Direito, contribuindo para que as normas jurídicas possam ser aplicadas de forma mais eficaz e em consonância com as normas constitucionais.

Para a obtenção dos resultados almejados pela pesquisa, o método de abordagem seguido foi o empírico-dialético ${ }^{1}$, utilizando-se de pesquisa bibliográfica e legislativa, tendo como pano de fundo um sistema de referência pautado no giro linguístico, representado por meio do Constructivismo Lógico-Semântico de Paulo de Barros Carvalho².

\section{Principiologia jurídica pós-moderna: Os conceitos jurídicos indeterminados e o ativismo judicial}

Após a Revolução Industrial, principalmente a partir da segunda metade do século $X X$, inicia-se um período de mudanças sem precedentes na história do pensamento jurídico, trata-se da pós-modernidade ${ }^{3}$, período em que ocorreu a

\footnotetext{
1 Para Lourival Vilanova, "os objetos culturais, entre os quais se aloja o direito, são todos aqueles que estão na experiência, tendo existência real, contudo sempre valiosos, positiva ou negativamente. $O$ ato gnosiológico próprio é a "compreensão" e o método da correspondente ciência é o "empírico-dialético"” (VILANOVA, 2008, p.82).

2Segundo Paulo de Barros Carvalho "[...] o Constructivismo Lógico-Semântico é, antes de tudo, um instrumento de trabalho, modelo para ajustar a precisão da forma à pureza e à nitidez do pensamento; meio e processo para a construção rigorosa do discurso, no que atende, em certa medida, a um dos requisitos do saber científico tradicional. Acolhe, com entusiasmo, a recomendação de Norberto Bobbio, segundo a qual não haverá ciência ali onde a linguagem for solta e descomprometida. O modelo constructivista se propõe amarrar os termos da linguagem, segundo esquemas lógicos que deem firmeza à mensagem, pelo cuidado especial com o arranjo sintático da frase, sem deixar de preocuparse com o plano do conteúdo, escolhendo as significações mais adequadas à fidelidade da enunciação(CARVALHO, 2014. p.2).

${ }^{3}$ Segundo Valter Moura do Carmo e Ewerton Ricardo Messias: "Tal período, denominado como pósmodernidade é caracterizado pela socialização e pela constitucionalização do Direito, assumindo, a principiologia constitucional, o lugar antes ocupado pelo positivismo jurídico, representado pelas codificações" (CARMO; MESSIAS, 2017, p. 191).
}

Revista de Direitos Fundamentais \& Democracia, Curitiba, v. 25, n. 3, p. 209-231, set./dez. 2020 
socialização e a constitucionalização do Direito, com a principiologia constitucional assumindo o lugar antes ocupado pelo positivismo jurídico.

A pós-modernidade é caracterizada pela irradiação das normas (princípios e regras $)^{4}$ constitucionais sobre todo o ordenamento jurídico ${ }^{5}$, neste sentido as normas contidas na Constituição Federal, principalmente as normas de direitos e garantias fundamentais, irradiam-se por todo o ordenamento jurídico, informando os limites a serem observados para a garantia dos direitos fundamentais que qualificam um Estado Democrático de Direito.

Dessa forma, os princípios passaram a possuir força normativa, a tal nível que a inobservância de um princípio, de acordo com o seu grau de importância, pode representar atuação contra todo o sistema jurídico, já que "[...] violar um princípio é muito mais grave que transgredir uma norma" (MELLO, 2013, p. 975).

Conforme se pode verificar a pós-modernidade, vivenciada na atualidade, caracteriza-se como o momento da principiologia jurídica, dos direitos fundamentais e da consolidação da democracia.

Há, então, um intenso debate não só a respeito da dogmática jurídica, mas, também, a respeito da técnica legislativa utilizada na construção dos enunciados jurídicos.

No sistema jurídico ${ }^{6}$, é comum a verificação de enunciados jurídicos elaborados por meio da utilização da técnica legislativa dos conceitos indeterminados, ou seja, elaborados mediante a utilização de fórmulas abertas e de conceitos indeterminados, carentes de um preenchimento valorativo, vez que construídos com uso de termos que se ajustam a inúmeros significados. Para Karl Engish os conceitos jurídicos indeterminados são "[...] conceitos cujo conteúdo e a extensão são em larga medida incertos" (ENGISH, 1988, p. 208). Tércio Sampaio Ferraz Júnior define

\footnotetext{
${ }^{4}$ Para Robert Alexy a "[...] distinção entre regras e princípios é uma distinção qualitativa, e não uma distinção de grau", sendo que [...] o ponto decisivo para a distinção entre regras e princípios é que os princípios são mandados de otimização enquanto que as regras tem o caráter de mandados definitivos. [...]Ao reconhecer o alto grau de abstração dos princípios, Alexy afirma que, em um caso concreto, diante do conflito da proibição trazida por um princípio com a permissão trazida por outro, o que ocorrerá é que um princípio cederá ao outro, situação que pode se inverter em outro caso fático, sob condições diferentes. [...] Por outro lado, reconhecendo o relativo grau de abstração das regras, Robert Alexy observa que, no caso concreto, diante de duas regras com consequências jurídicas contraditórias uma deverá ser declarada inválida" (ALEXY, 2008, p.90-94).

5 Por ordenamento jurídico entende-se o conjunto de enunciados prescritivos, os quais formam o chamado direito positivo (CARMO; MESSIAS, 2017, p. 195).

${ }^{6}$ Por sistema jurídico ou simplesmente Direito pode-se compreender o conjunto formado pelo ordenamento jurídico, composto pelos enunciados prescritivos, formando o chamado direito positivo; e pela ciência do direito, composta pelos enunciados descritivos ou normas, que surgem a partir da atuação humana na interpretação dos enunciados prescritivos, visando eliminar indeterminações e contradições existentes no âmbito do Direito ou sistema jurídico (CARMO; MESSIAS, 2017, p.195).

Revista de Direitos Fundamentais \& Democracia, Curitiba, v. 25, n. 3, p. 209-231, set./dez. 2020
} 
conceitos jurídicos indeterminados como "[...] os que manifestam vaguidade, isto é, não é possível, de antemão, determinar-lhes a extensão denotativa. Assim, por exemplo, as expressões: repouso noturno, ruído excessivo, perigo iminente, etc" (FERRAZ JÚNIOR, 2007, p. 331).

Os conceitos jurídicos indeterminados podem ser conceitos empíricos ou conceitos de valor. Os empíricos reportam-se a fatos, estados ou situações da natureza ou da realidade como, por exemplo, noite, dia, embriaguez, morte, risco etc. Os valorativos exigem do intérprete ou do aplicador do direito uma apreciação em termos valorativos como, por exemplo, interesse público, motivo fútil, maus tratos, conduta desonrosa, eficiência pública, prudência, discrição etc.

Diante dos conceitos jurídicos indeterminados, os órgãos aplicadores do direito deparam-se com a dificuldade de emitir suas decisões a partir da mera subsunção de um fato da vida a um enunciado jurídico prescritivo, ou seja, a um conceito jurídico fixo, expressamente escrito no direito positivo.

A hermenêutica jurídica assume características específicas, vez que, diante dos conceitos jurídicos indeterminados, é exigida do juiz uma postura altamente construtiva do conteúdo semântico dos enunciados sob análise, do que uma atitude simplesmente declarativa, arraigada na subsunção do fato da vida à norma jurídica positivada. Neste sentido Gregório Robles Morchón (2005, p. 53) afirma que:

[...] os juristas não se limitam a ler o texto jurídico com olhos de profissionais capazes de entender completamente seu sentido; são eles, além disso, os encarregados de interpretar as normas. A interpretação das normas cabe especialmente a determinados juristas: aqueles que ocupam órgãos de decisão (como os juízes) e os que se dedicam à ciência do direito (os cientistas do direito).

É justamente aqui que surge a figura do ativismo judicial, que se revela como um fenômeno pós-moderno caracterizado pela forte atuação do Poder Judiciário nas relações sociais, de forma a regular políticas públicas e intervir em aspectos da vida privada dos indivíduos.

\section{ATIVISMO JUDICIAL, LIVRE CONVENCIMENTO MOTIVADO DO JUIZ E PRÓ ATIVIDADE JUDICIAL}

Nesse ponto é preciso diferenciar as espécies ativismo judicial e livre convencimento motivado do juiz, tendo por base a judicialização. 
A judicialização revela-se como um fenômeno em que o Poder Judiciário é provocado a manifestar-se sobre demandas existentes na sociedade, ou seja, pessoas físicas ou jurídicas, de direito público ou privado, provocam o Poder Judiciário mediante a propositura de uma Ação Processual, para que o mesmo, no exercício constitucional da prestação jurisdicional, manifeste-se acerca da demanda colocada sob sua análise e julgamento, assim, a judicialização ocorre independentemente da vontade do Poder Judiciário.

$\mathrm{Na}$ judicialização, o Poder Judiciário atua, inclusive, com o exercício do livre convencimento motivado do juiz, porque é o que lhe cabe constitucionalmente fazer, sem alternativa (BARROSO, 2012, p. 25). Acerca do livre convencimento motivado, Nelson Nery Júnior (2004, p. 519) afirma que o juiz:

[...] é soberano na análise das provas produzidas nos autos. Deve decidir de acordo com o seu convencimento. Cumpre ao magistrado dar as razões de seu convencimento. Decisão sem fundamentação é nula pleno jure (CF 93 IX). Não pode utilizar-se de fórmulas genéricas que nada dizem. Não basta que o juiz, ao decidir, afirme que defere ou indefere o pedido por falta de amparo legal; é preciso que diga qual o dispositivo de lei que veda a pretensão da parte ou interessado e porque é aplicável no caso concreto.

É nesse aspecto que o exercício do livre convencimento motivado afasta-se do ativismo judicial, pois o livre convencimento motivado ocorre diante da judicialização, ou seja, ocorre quando há provocação do Poder Judiciário para que se manifeste no âmbito do processo e nos limites dos pedidos formulados, consubstanciando-se no dever do Poder Judiciário atuar de forma eficiente e adequada na prestação jurisdicional, conforme previsto no artigo 5, XXXV, da Constituição Federal de 1988 (BRASIL, 1988).

Diante da judicialização, o juiz livremente analisa as provas produzidas nos autos e forma sua convicção, fundamentando-a com fórmulas específicas contidas no dispositivo de lei que veda ou autoriza determinada pretensão e motivando-a com o porquê tal dispositivo de lei é aplicável no caso concreto.

No entanto, a livre convicção motivada do juiz não é tão livre como alguns pensam, exemplo disso são as súmulas vinculantes, previstas no artigo 103-A da Constituição Federal de 1988, cuja regulamentação está contida na Lei n 11.417/2006 (BRASIL, 2006). Tais súmulas vinculam os juízes e tribunais aos seus enunciados, sob pena de, diante de sua desconsideração, a decisão judicial ser cassada, conforme previsão contida no $\S^{\circ}$ do artigo 103-A da Constituição Federal de 1988 (BRASIL, 
1988).

$\mathrm{Na}$ pós-modernidade, as súmulas vinculantes revelam-se como um forte ativismo judicial nas relações sociais, vez que o Supremo Tribunal Federal (STF) tem criado um considerável número de súmulas vinculantes, de forma a atuar como criador do Direito, legislando, em sentido amplo, e limitando a interpretação das normas, pelos tribunais e pelos membros do Poder Judiciário, nos casos concretos.

Diferentemente da judicialização, em que o Poder Judiciário manifesta-se após ser provocado, no ativismo judicial nem sempre o Poder Judiciário é previamente provocado, em muitos casos ele se antecipa a qualquer provocação, ou seja, age sem que haja qualquer provocação, no que tange à interpretação da norma.

A justificativa para tal antecipação por parte do Poder Judiciário, no mais das vezes, calca-se na alegação de inércia dos Poderes Legislativo e Executivo, situações em que o Poder Judiciário age para decidir e preencher lacunas normativas deixadas por tais Poderes constituídos.

No ativismo judicial, o intérprete do Direito, ao analisar a tese jurídica ou o plano fático em que se desenvolve a lide, extrapola a esfera do contexto normativo, de forma a impor sua posição interpretativa da norma, fazendo prevalecer sua vontade subjetiva sobre o objeto normativo, em detrimento da interpretação dada por outro Poder constituído, ultrapassando, então, os limites do sistema positivado.

O jurista Elival da Silva Ramos (2010, p. 129) trata o ativismo judicial com base na intervenção do Judiciário nas outras esferas de poder, definindo-o como o exercício da função jurisdicional para "[...] além dos limites impostos pelo próprio ordenamento que incumbe, institucionalmente, ao Poder Judiciário fazer atuar, importando na desnaturação da atividade típica do Poder Judiciário, em detrimento dos demais Poderes".Lênio Streck (2014, p. 50) esclarece que quando o Judiciário atua fora da órbita, para a qual foi originariamente legitimado, será ativista, pois estará agindo fora dos limites impostos pela autonomia do Direito.Como exemplo, pode ser citada a recente Súmula 611 do Superior Tribunal de Justiça (STJ), a qual será objeto de análise no próximo item.

Resultado disso é o agigantamento do poder atribuído ao Judiciário, por meio da legitimação da atuação pautada em exacerbado subjetivismo, que afasta as bases contidas no sistema jurídico, de forma a proporcionar o surgimento de uma ditadura do Poder Judiciário, que passa a invadir a esfera de competência dos outros Poderes constituídos (CARMO; MESSIAS, 2017, p. 198). 
De outro giro, na pró atividade judicial, o intérprete, diante de uma demanda caracterizada por um alto nível de subjetividade, busca a melhor interpretação para a resolução da demanda no ordenamento jurídico, primando pela manutenção da ordem do sistema, por meio de uma interpretação objetiva do material jurídico, em detrimento de sua subjetividade interpretativa, pois a interpretação da norma somente se legitima quando realizada com base no ordenamento jurídico e não contra ele.

A regra é que a discricionariedade judicial ocorra em situações excepcionais, diante da ilegitimidade do julgador para criar o Direito, uma vez que tal função incumbe ao Poder Legislativo, por meio dos representantes eleitos pelo povo.

A atuação judicial deve se dar de forma a extrair o máximo das potencialidades do direito positivo e da ciência do direito, sem, contudo, invadir o campo da criação livre do Direito (BARROSO, 2012, p. 26), sob pena de rompimento com o sistema democrático de direito, tornando-se inconstitucional.

A atuação judicial desmedida traz, como consequência, o agigantamento do poder atribuído ao Judiciário, por meio da legitimação da atuação pautada em exacerbado subjetivismo, portanto, afastada das bases contidas no sistema jurídico, de forma a proporcionar o surgimento de uma ditadura desse Poder, a qual passa a invadir a esfera de competência dos outros Poderes constituídos, quais sejam o Poder Executivo e o Poder Legislativo.

\section{ATIVISMO JUDICIAL: A SÚMULA 611 DO SUPERIOR TRIBUNAL DE JUSTIÇA E O DESRESPEITO A DIREITOS FUNDAMENTAIS}

No Brasil, é comum que órgãos do Poder Executivo realizem a instauração de procedimentos investigatórios, em detrimento de seus administrados, a partir de mera denúncia anônima, relativizando a expressa vedação constitucional ao anonimato, prevista no Art. $5^{\circ}$, inciso IV, da Constituição Federal de 1988. Por razão óbvia, os constituintes originários fizeram constar a vedação ao anonimato do texto da Constituição Federal brasileira, qual seja evitar que, por meio do anonimato, pessoas possam, impunemente, caluniar, difamar ou injuriar terceira pessoa de forma gratuita e mentirosa, sem o risco de responder por sua ação criminosa, vez que o Código Penal brasileiro - Decreto-Lei $n^{\circ} 2.848 / 1940$, editado 48 (quarenta e oito) anos antes da Constituição Federal brasileira, prevê tais condutas como criminosas em seus Arts. 138 a 140 (BRASIL, 1940). 
No entanto, mesmo diante de tal vedação constitucional, como dito, órgãos do Poder Executivo vêm instaurando procedimentos investigatórios, em detrimento de seus administrados, a partir de mera denúncia anônima, sendo que, para tanto, balizam seus atos em apenas um dos requisitos de validade do ato administrativo, qual seja, a competência da administração pública para instaurar procedimentos investigatórios em detrimento dos administrados, mesmo que calcada em denúncia anônima, tendo, como base principiológica, o axioma da supremacia do interesse público.

O mais grave é que o STJ, por meio de claro ativismo judicial, reconheceu tal prática como legal, oportunidade em que aprovou, em 09 de maio de 2018, a Súmula de número $611^{7}$, a qual foi publicada no Diário Oficial de Justiça no dia 14 de maio de 2018. Tal Súmula baseou-se no julgamento do Agravo Regimental no Recurso Especial 1.307.503/RR, ocasião em que o relator, Ministro Mauro Campbell Marques, decidiu não haver ilegalidade "[...] na instauração de processo administrativo com fundamento em denúncia anônima, por conta do poder-dever de autotutela imposto à Administração e, por via de consequência, ao administrador público" (Agravo Regimental no Recurso Especial $n^{\circ} 1.307 .503$ - RR, Segunda Turma, Relator Ministro Mauro Campbell Marques, julgado em 06/08/2013).

Ora reconhecer que todo e qualquer ato administrativo (ato do Estado em detrimento do administrado) deve prosseguir seu curso, ou seja, deve ser processado, ainda que comprovadamente desprovido dos requisitos essenciais de validade (legalidade), principalmente, os requisitos motivo ${ }^{8}$ e finalidade ${ }^{9}$ do ato administrativo,

\footnotetext{
${ }^{7}$ Súmula 611 - Desde que devidamente motivada e com amparo em investigação ou sindicância, é permitida a instauração de processo administrativo disciplinar com base em denúncia anônima, em face do poder-dever de autotutela imposto à Administração (BRASIL, 2018).

${ }^{8} \mathrm{O}$ requisito motivo é o pressuposto fático e jurídico que dá causa ao ato administrativo, ou seja, é a verificação da existência de um dispositivo legal e de fatos concretos que ensejam a prática do ato. É primazia de fato e de direito do ato administrativo, de que todo ato administrativo deve ter um motivo lícito, baseado em lei e em fatos concretos, não podendo, tal motivo, estar permeado por denúncias anônimas; perseguições ou favoritismos por parte do agente público que o pratica.

${ }^{9} \mathrm{O}$ requisito finalidade está diretamente ligado ao princípio da impessoalidade. Finalidade é, portanto, o resultado que se espera encontrar com a prática de determinado ato administrativo. É o resultado que se encontrou após a sua realização, é a concretização do ato administrativo. Esta definição de pronto diferencia finalidade de motivo uma vez que a finalidade é o resultado encontrado e o motivo ocorre antes da prática do ato. A finalidade do ato administrativo é aquela que a lei indica explícita ou implicitamente. É o efeito jurídico mediato, ou seja, é o resultado que a administração deseja com a prática do ato. Ela pode ser entendida por dois prismas jurídicos diversos. Em sentido amplo, quando o ato jurídico deverá assegurar a observância do ato público, este deve ser sempre apresentado em consonância com a finalidade pública. Em sentido restrito o ato administrativo deverá ser o resultado específico e estabelecido em lei. É a lei que define a finalidade a ser atingida pelo ato administrativo. Não há liberdade para a administração pública. Vedação estabelecida no Art. $2^{\circ}$, alínea "e", do parágrafo único, da Lei $n^{\circ} 4.717 / 65$, o qual prevê que "o desvio de finalidade se verifica quando o agente pratica o ato visando a fim diverso daquele previsto, na regra de competência" (BRASIL, 1965). Para Hely Lopes Revista de Direitos Fundamentais \& Democracia, Curitiba, v. 25, n. 3, p. 209-231, set./dez. 2020
} 
não é prática característica de um Estado Democrático de Direito, como se caracteriza a República Federativa do Brasil, conforme previsto no Art. $1^{\circ}$, caput, da Constituição Federal de 1988; mas sim é prática de Regimes Ditatoriais, nos quais os atos administrativos são soberanos e inquestionáveis, ainda que, patentemente, inconstitucionais ou ilegais. luri Mattos de Carvalho assevera que os atos administrativos devem subordinar-se a alguns critérios para a sua realização, quais sejam:

\begin{abstract}
a) o ato discricionário deve buscar a realização ou a proteção de um direito fundamental, seja interesse coletivo ou interesse individual, sob pena de nulidade; b) se a decisão foi praticada para realizar direitos fundamentais, deve passar pelos testes impostos pelo princípio da proporcionalidade: adequação (idoneidade), necessidade e ponderação (proporcionalidade em sentido estrito) (CARVALHO I., 2007, p. 15).
\end{abstract}

A autora ainda conclui que "[...] o comprometimento da Administração Pública com a realização do interesse público é o compromisso com um procedimento, um método para se alcançar a decisão administrativa que melhor realize os direitos fundamentais, levando-se em consideração o caso concreto" (CARVALHO I., 2007, p. 15).

Em um Estado Democrático de Direito o axioma da supremacia do interesse público não é e não deve ser absoluto, pois ele não exclui ou afasta a existência de princípios, inclusive daqueles destinados a:

[...] assegurar a propriedade e a liberdade privadas. [...] Como decorrência, não se pode afirmar, de modo generalizado e abstrato, algum tipo de supremacia absoluta produzida aprioristicamente em favor de algum titular de posição jurídica. Nem o Estado nem qualquer sujeito privado são titulares de posição jurídica privilegiada em face de outrem. Todo e qualquer direito, interesse, poder, competência ou ônus são limitados sempre pelos direitos fundamentais. Nenhuma decisão administrativa ofensiva dos direitos fundamentais pode ser reconhecida como válida. [...] Qualquer invocação genérica do interesse público deve ser repudiada por ser incompatível com o Estado Democrático de Direito e a consagração dos direitos fundamentais (JUSTEN FILHO, 2016, p. 52-53; 67).

Assim, o axioma da supremacia do interesse público deve ser interpretado em conjunto com os fundamentos da República Federativa do Brasil, mormente, com o fundamento da dignidade da pessoa humana, previsto no Art. $1^{\circ}$, inciso III, da Constituição Federal de 1988; bem como com os direitos fundamentais, como, por 
exemplo, o direito à vida digna e à inviolabilidade da intimidade, da honra, da vida privada e da imagem da pessoa humana, previstos, respectivamente, no Art. $5^{\circ}$, caput e inciso X, da Constituição Federal de 1988.

Assim, em um Estado Democrático de Direito, como é a República Federativa do Brasil, a legalidade dos atos administrativos está completamente subordinada ao preenchimento dos requisitos de legalidade do ato administrativo. Dessa forma, em que pese o poder de autotutela do Estado em relação aos atos administrativos, a análise acerca da legalidade, ou seja, a análise sobre o preenchimento dos requisitos essenciais de legalidade de determinado ato administrativo, diante da judicialização, deve ser realizada pelo Poder Judiciário, mediante a aplicação dos princípios da legalidade, da razoabilidade e da proporcionalidade, visando à conformação entre o interesse público (intersubjetividade), o fundamento da República Federativa do Brasil (dignidade da pessoa humana) e os direitos fundamentais dos administrados (vida digna, inviolabilidade da intimidade, da honra, da vida privada e da imagem), pois uma das formas de exercício da soberania dá-se por meio das decisões proferidas pelo Poder Judiciário nas resoluções de conflitos de direitos existentes no seio da sociedade. Nesse ponto, o Tribunal de Justiça do Estado de São Paulo possui duas importantes decisões, por meio das quais se verifica que:

\footnotetext{
Não há dúvida de que o Estado, ao exercitar sua soberania, prolatando decisões judiciais, o faz através do uso do processo, que é disciplinado pelo legislador ordinário, com obediência aos princípios constitucionais. (Apelação n 1038853-14.2014.8.26.0053, $3^{\mathrm{a}}$ Câmara de Direito Público, Relator Desembargador Maurício Fiorito, julgado em 19/05/2015) (Apelação $n^{\circ}$ 1033670-62.2014.8.26.0053, $3^{\text {a }}$ Câmara de Direito Público, Relator Desembargador Maurício Fiorito, julgado 03/11/2015).
}

Assim, o Poder Judiciário deve realizar a análise acerca da legalidade, ou seja, a análise sobre o preenchimento dos requisitos essenciais de legalidade de determinado ato administrativo, mediante a aplicação dos princípios da legalidade, da razoabilidade e da proporcionalidade, visando à conformação entre o interesse público (intersubjetividade), o fundamento da República Federativa do Brasil (dignidade da pessoa humana) e os direitos fundamentais dos administrados (vida digna, inviolabilidade da intimidade, da honra, da vida privada e da imagem), principalmente, quando o conflito de direitos existente seja qualificado por uma relação processual em que sejam partes o Estado e um administrado, onde, inequivocamente, há vulnerabilidade do administrado em relação ao Estado, necessitando que o Poder 
Judiciário possa equilibrar, no exercício da Jurisdição, tal relação processual por meio do controle de legalidade, conformando o eventual interesse público aos fundamentos da República Federativa do Brasil e aos direitos fundamentais dos cidadãos brasileiros, com base nos princípios da legalidade, da razoabilidade e da proporcionalidade. Está é a inteligência da Súmula 473 do Supremo Tribunal Federal (STF) ${ }^{10}$.

\section{INTERESSE PÚBLICO, PRUDÊNCIA E DISCRIÇÃO: CONCEITOS JURÍDICOS INDETERMINADOS VALORATIVOS INDISPENSÁVEIS À CONSTITUCIONALIDADE DA SÚMULA 611 DO STJ}

Prefacialmente se faz necessário o entendimento acerca da definição do que seja interesse público, vez que se trata de um conceito jurídico indeterminado valorativo. Nesse aspecto, Marçal Justen Filho assevera que, antes de delimitar a definição do que seja interesse público, importante se faz determinar o que não é interesse público. Nesse sentido, o autor disserta que:

Não é cabível confundir interesse público com interesse estatal, o que geraria
um raciocínio circular: o interesse seria público porque atribuído ao Estado, e
seria atribuído ao Estado por ser público. Essa concepção é incompatível com
a Constituição e a maior evidência disso reside na existência de interesses
públicos não estatais (o que envolve, em especial, o chamado terceiro setor,
composto pelas organizações não governamentais). [...] O interesse público
não consiste no "interesse do aparato estatal". O Estado, como sujeito de
direito, pode ter interesses de modo semelhante ao que ocorre com qualquer
sujeito privado, que age segundo uma lógica de conveniência. [...] Não se pode
admitir que o interesse público seria o interesse da sociedade, entendida como
algo inconfundível com o mero somatório dos indivíduos. A tese pressuporia
que o todo (conjunto de indivíduos) seria mais do que o resultado da soma das
unidades. Embora a sociedade não se confunda com os indivíduos que a
integram (sic), a tese não pode ser aceita em virtude de sua natureza
antidemocrática. Gera a possibilidade de reconhecer como interesse público
algo desvinculado de qualquer interesse individual concreto. A desvinculação
entre a dimensão individual e o interesse público contém o germe do
autoritarismo. É o primeiro passo para o reconhecimento de interesses
supraindividuais de configuração totalitária e cuja lamentável afirmação se
verificou nos regimes do nacional-socialismo alemão e do stalinismo. [...] Outra
hipótese seria considerar que o interesse público é o resultado do interesse
privado da totalidade dos sujeitos privados. [...] Essa concepção é inútil,
porque a unanimidade nunca seria atingida. Bastaria um único sujeito ter
interesse divergente do restante para impedir o surgimento do interesse
público. [...] Uma outra solução seria, então, afirmar que o interesse público é o
interesse privado comum e homogêneo da maioria da população. Esse
entendimento também não pode ser aceito, porque conduz à opressão. Numa

${ }^{10} \mathrm{~A}$ administração pode anular seus próprios atos, quando eivados de vícios que os tornam ilegais, porque deles não se originam direitos; ou revogá-los, por motivo de conveniência ou oportunidade, respeitados os direitos adquiridos, e ressalvada, em todos os casos, a apreciação judicial (BRASIL, 1969).

Revista de Direitos Fundamentais \& Democracia, Curitiba, v. 25, n. 3, p. 209-231, set./dez. 2020 
democracia, o interesse público não pode ser apenas o interesse da maioria da população. Isso acarretaria a destruição dos interesses das minorias. E um Estado Democrático caracteriza-se pela tutela tanto dos interesses das maiorias como das minorias. A vontade da maioria é preponderante dentro de certos limites, eis que também se protegem os interesses da minoria, tudo segundo parâmetros constitucionalmente fixados. Ou seja, o conceito de interesse público não se vincula a questões apenas quantitativas (JUSTEN FILHO, 2016, p. 58-59).

Interesse público é aquele relativo às questões essenciais, cuja relevância dispensa o requisito da maioria, por ser indisponível. Assim, o interesse é "[...] público porque é indisponível, porque não pode ser colocado em risco, porque sua natureza exige que seja realizado" (JUSTEN FILHO, 2016, p. 61). Dessa forma, o direito não é indisponível porque é púbico, mas sim é público porque é indisponível (JUSTEN FILHO, 2016, p. 60).

No que se refere à cautela que deve qualificar as investigações preliminares baseadas, cabe referir, por oportuno, que o STJ, em momento pretérito, ao apreciar a questão da delação anônima, analisada em face do art. $5^{\circ}$, IV, in fine, da Constituição da República (BRASIL, 1988), pronunciou-se no sentido de considerá-la juridicamente possível, no entanto, asseverou que, para tal, o Estado, ao agir em função de comunicações revestidas de caráter apócrifo, deveria atuar com cautela, de forma a evitar a consumação de situações que possam ferir, injustamente, direitos de terceiros. Nesse sentido:

\begin{abstract}
EMENTA. CRIMINAL. RHC. NOTITIA CRIMINIS ANÔNIMA. INQUÉRITO POLICIAL. VALIDADE. A delatio criminis anônima não constitui causa da ação penal que surgirá, em sendo caso, da investigação policial decorrente. Se colhidos elementos suficientes, haverá, então, ensejo para a denúncia. É bem verdade que a Constituição Federal (art. $5^{\circ}$, IV) veda o anonimato na manifestação do pensamento, nada impedindo, entretando, mas, pelo contrário, sendo dever da autoridade policial proceder à investigação, cercando-se, naturalmente, de cautela. (Recurso Ordinário em Habeas Corpus $n^{\circ} 7.329$ - GO. Relator Ministro Fernando Gonçalves, Sexta Turma, julgado em 16/04/1998, grifo nosso).
\end{abstract}

O STJ firmou jurisprudência no sentido de exigir prudência e discrição para a instrução de investigação preliminar baseada em denúncia anônima, assim decidiu o Ministro Nefi Cordeiro, por ocasião do julgamento do Habeas Corpus $n^{\circ} 258.819 / S P$, oportunidade em que, dentre outras considerações, asseverou que:

[...]

3. Não é ilegal a autoridade policial, ante delação anônima, adotar medidas informais destinadas a apurar, previamente, em averiguação sumária, com prudência e discrição, a possível ocorrência de eventual situação de ilicitude 
penal, desde que o faça com o objetivo de conferir a verossimilhança dos fatos nela denunciados, em ordem a promover, então, em caso positivo, a formal instauração do inquérito policial.

[...] (Habeas Corpus no 258.819 - SP. Relator Ministro Nefi Cordeiro, Sexta Turma, julgado em 19/04/2016).

Em relação à instauração de procedimento investigativo preliminar, penal ou administrativo, com base em denúncia anônima, o STF possui jurisprudência consolidada no sentido de que é possível a instauração de tais procedimentos investigativos com base em denúncia anônima, no entanto, a referida jurisprudência é clara em condicionar que tais procedimentos sejam revestidos de informalidade e que as autoridades responsáveis pela realização de sua instrução atuem com prudência e discrição, conforme asseverou o Ministro Celso de Mello, por ocasião do julgamento do Recurso Ordinário no Habeas Corpus n 117.988:

\begin{abstract}
As autoridades públicas não podem iniciar qualquer medida de persecução (penal ou disciplinar), apoiando-se, unicamente, para tal fim, em peças apócrifas ou em escritos anônimos. É por essa razão que o escrito anônimo não autoriza, desde que isoladamente considerado, a imediata instauração de 'persecutio criminis'. - Nada impede que o Poder Público, provocado por delação anônima ('disque-denúncia', p. ex.), adote medidas informais destinadas a apurar, previamente, em averiguação sumária, 'com prudência e discrição', a possível ocorrência de eventual situação de ilicitude penal, desde que o faça com o objetivo de conferir a verossimilhança dos fatos nela denunciados, em ordem a promover, então, em caso positivo, a formal instauração da 'persecutio criminis', mantendo-se, assim, completa desvinculação desse procedimento estatal em relação às peças apócrifas. (Recurso Ordinário em Habeas Corpus no 117.988 - RS. Relator Ministro Gilmar Mendes. Relator para o Acórdão Ministro Celso de Mello, Segunda Turma, julgado em 16/12/2014, grifo nosso).
\end{abstract}

O mesmo Ministro, por ocasião do julgamento do Agravo Regimental no Habeas Corpus no 135.969 - MA, voltou a reforçar o entendimento de que o procedimento investigativo preliminar deve ser instruído com prudência e discrição, oportunidade em que foi lavrada a seguinte ementa:

EMENTA: "HABEAS CORPUS" - SUSTENTAÇÃO ORAL EM SEDE DE "AGRAVO REGIMENTAL" - INADMISSIBILIDADE CONSTITUCIONALIDADE DA VEDAÇÃO REGIMENTAL (RISTF, ART. 131, § $\left.2^{\circ}\right)$ - SUPOSTA FUNDAMENTAÇÃO DO ATO DECISÓRIO QUE DETERMINOU A INTERCEPTAÇÃO TELEFÔNICA EXCLUSIVAMENTE EM DELAÇÃO ANÔNIMA - INOCORRÊNCIA - PERSECUÇÃO PENAL E DELAÇÃO ANÔNIMA - VIABILIDADE, DESDE QUE A INSTAURAÇÃO FORMAL DO PROCEDIMENTO INVESTIGATÓRIO E A PRODUÇÃO PROBATÓRIA TENHAM SIDO PRECEDIDAS DE AVERIGUAÇÃO SUMÁRIA, "COM PRUDÊNCIA E DISCRIÇÃO", DESTINADA A APURAR A VEROSSIMILHANÇA DOS FATOS DELATADOS E DA RESPECTIVA AUTORIA - APURAÇÃO PRELIMINAR EFETIVADA PELA AUTORIDADE COMPETENTE - DOUTRINA - PRECEDENTES DO SUPREMO TRIBUNAL 
FEDERAL - ALEGAÇÃO DE PERDA DA CADEIA DE CUSTÓDIA REFERENTE À PROVA PENAL - MATÉRIA NÃO EXAMINADA PELO SUPERIOR TRIBUNAL DE JUSTIÇA - IMPETRAÇÃO COM APOIO EM FUNDAMENTOS NÃO APRECIADOS PELO TRIBUNAL APONTADO COMO COATOR: HIPÓTESE DE INCOGNOSCIBILIDADE, NESSE PONTO, DO "WRIT" CONSTITUCIONAL - PARECER DA PROCURADORIA-GERAL DA REPÚBLICA PELO INDEFERIMENTO DO PEDIDO - RECURSO DE AGRAVO IMPROVIDO. (Agravo Regimental no Habeas Corpus no 135.969 MA. Relator Ministro Celso de Mello, Segunda Turma, julgado em 29/11/2016, grifo nosso).

Diante da jurisprudência firmada no âmbito dos Tribunais superiores, imprescindível se faz definir o que sejam prudência e discrição vez que se tratam de conceitos jurídicos indeterminados valorativos que, conforme já explicitado, exigem do operador do Direito uma postura altamente construtiva do seu conteúdo semântico, e não só uma atitude simplesmente declarativa.

Tendo por esteio a cidadania $^{11}$ e a dignidade da pessoa humana ${ }^{12}$, fundamentos da República Federativa do Brasil, previstos no Art. $1^{\circ}$, incisos II e III, da Constituição Federal de 1988, bem como os direitos fundamentais de vedação ao anonimato e de inviolabilidade da intimidade, da vida privada, da honra e da imagem das pessoas, previstos, respectivamente, no Art. $5^{\circ}$ incisos, IV e X, da Constituição Federal de 1988 (BRASIL, 1988) buscar-se-á, no âmbito da presente pesquisa, construir as definições dos conceitos jurídicos indeterminados valorativos prudência e discrição, assim como foi feito com o conceito jurídico indeterminado valorativo interesse público.

A prudência pode ser entendida como sinônimo de temperança, moderação, sensatez ou cautela. No Direito, liga-se à virtude de um agir de forma justa e ponderada, ou seja, liga-se à virtude de um agir precavido, de forma a analisar as variáveis existentes e avaliar suas possíveis consequências antes de adotar uma determinada decisão, visando evitar situações que possam ferir direitos de terceiros.

Por sua vez, a discrição esta ligada a ideia de um agir de forma reservada,

\footnotetext{
${ }^{11}$ José Afonso da Silva disserta que a cidadania "consiste na consciência de pertinência à sociedade estatal como titular dos direitos fundamentais, da dignidade como pessoa humana, da integração participativa no processo do poder com a igual consciência de que essa situação subjetiva envolve também deveres de respeito à dignidade do outro, de contribuir para o aperfeiçoamento de todos. Essa cidadania é que requer providências estatais no sentido da satisfação de todos os direitos fundamentais em igualdade de condições" (SILVA, 1999, p. 11).

12 Vida digna é aquela vivida com dignidade, sendo, a dignidade, entendida como um fim material, um objetivo, "[...] que se concretiza no acesso igualitário e generalizado aos bens[...] que fazem com que a vida seja "digna" de ser vivida" (FLORES, 2009, p.37), tais como a saúde;a segurança;o meio ambiente ecologicamente equilibrado;a educação; a inviolabilidade da intimidade, da vida privada, da honra, e da imagem das pessoas, entre outros direitos fundamentais descritos no Art. $5^{\circ}$, caput, incisos e parágrafos, da Constituição Federal de 1988 (BRASIL, 1988).
}

Revista de Direitos Fundamentais \& Democracia, Curitiba, v. 25, n. 3, p. 209-231, set./dez. 2020 
sem chamar a atenção. O agir com discrição visa evitar a exposição desnecessária, desarrazoada, inconstitucional ou ilegal da imagem de terceira pessoa, bem como, de igual forma, visa evitar a desarrazoada, inconstitucional ou ilegal violação da intimidade, da vida privada e da honra da pessoa.

Portanto, a jurisprudência pacífica do STF e do STJ, que admite a instauração de investigação preliminar ou prévia com base em denúncia anônima, exige a prévia realização, com prudência, de diligências discretas voltadas a verificar a verossimilhança da denúncia anônima, e isso não se dá ao acaso, mas sim em virtude da observância aos fundamentos da cidadania e da dignidade da pessoa humana, previstas, respectivamente, no Art. $1^{\circ}$, incisos II e III, da Constituição Federal de 1988, como fundamentos da República Federativa do Brasil, enquanto Estado Democrático de Direito que é, fundamentos, estes, dos quais decorrem os direitos fundamentais à intimidade, a vida privada e a honra, previstos no Art. $5^{\circ}$, inciso $X$, da Constituição Federal de 1988 (BRASIL, 1988), dentro outros direitos fundamentais.

Nesse sentido, os atos administrativos e as decisões administrativas devem ser analisados à luz dos princípios da razoabilidade e da proporcionalidade e, no caso específico, com observância aos princípios da cidadania e da dignidade da pessoa humana, nos termos do artigo $1^{\circ}$, incisos II e III, da Constituição Federal de 1988. No dizer de José Joaquim Gomes Canotilho:

[...] ao consagrar a dignidade da pessoa humana como um dos
fundamentos do Estado Democrático (e social) de Direito (art. $1^{\circ}$, III), a CF
de 1988, além de ter tomado uma decisão fundamental a respeito do
sentido, da finalidade e da justificação do próprio Estado e do exercício
do poder estatal, reconheceu categoricamente que o Estado existe em
função da pessoa humana, e não o contrário. Da mesma forma, não foi por
acidente que a dignidade não constou do rol dos direitos e garantias
fundamentais, tendo sido consagrada em primeira linha como princípio (e
valor) fundamental, que, como tal, deve servir de norte ao intérprete, ao qual
incumbe a missão de assegurar-lhe a necessária força normativa
(CANOTILHO, 2013, p. 124, grifo nosso).

No controle de legalidade dos atos administrativos, a ser realizado pelo Poder Judiciário com base na Súmula 473 do STF, há que se sopesar a conformação constitucional dos direitos no sentido de sua máxima realização, especialmente considerando a peculiaridade da demanda sub judice. Assim, é sabido que o axioma da supremacia do interesse público norteia as decisões administrativas:

No entanto, as decisões administrativas devem se nortear, também, pelos princípios da razoabilidade e da proporcionalidade, inobservados no caso 
em tela. Com efeito, tratando-se de situação de extrema gravidade, o interesse público deve ceder, por razoabilidade, frente a outros princípios também caros à Administração como um todo, taisquais o da proteção à família (art. 226, da CR), da dignidade da pessoa humana (art. $1^{\circ}$, III, da CR) e da solidariedade (art. 30, I, da CR). (Apelação Cível n 1000606-46.2017.8.26.0024, 10ª Câmara de Direito Público, Relator Desembargador Marcelo Semer, julgado em. 13/11/2017, grifo nosso).

Nesta esteira também decidiu o Desembargador Nogueira Diefenthaler nos autos da Apelação n 1051082-98.2017.8.26.0053, ocasião em que asseverou que:

\begin{abstract}
Embora a norma refira-se à compatibilidade como interesse público, forçoso reconhecer que não se trata de imperativo absoluto no ordenamento pátrio, o qual deve ser conciliado com os demais dispositivos constitucional e legais acercada dignidade da pessoa, da proteção à família e à transferência do servidor público, especialmente o art. $1^{\circ}$, inciso III, e art. 226 da Constituição da República, o art. 130 da Constituição Paulista e os arts. 234 e 235 da Lei estadual n 10.261/08.

[...]

Embora a autoridade impetrada tenha apresentado informações no presente mandamus sustentando $o$ ato administrativo atacado, há de se ressaltar que a peculiaridade do caso presente impõe-nos a exigência do exercício exegético em torno dos artigos $1^{\circ}$, inciso III, e 226, caput e parágrafos, da Constituição da República, a fim de compatibilizar a necessidade do autor ao interesse público da Administração, tendo em vista uma situação excepcional que justifique a hipótese o que no caso presente restou devidamente demonstrado. Do mesmo modo, não socorre a Fazenda a alegação de que o interesse público possui o condão de indeferir o pleito. Antes de qualquer coisa, cabe ao Estado zelar pelaintegridade e união da família, como bem assinala o art. 226 e seguintes da Constituição Federal, sob pena de tornar letra mortaestes ditames constitucionais.Além disso, destaco que, não obstante as alegações do impetrado, com o acolhimento do pedido do autor,não se vislumbra ameaça, tampouco violação ao primado da continuidade e eficiência na prestação de serviço público em prolda coletividade. (Apelação $n^{\circ}$ 105108298.2017.8.26.0053, Relator Nogueira Diefenthaler, $5^{\text {a }}$ Câmara de Direito Público, julgado em 04/05/2017,grifo nosso).
\end{abstract}

De igual forma decidiu o Desembargador Fermino Magnani Filho nos autos da Apelação $n^{\circ}$ 1043828-74.2017.8.26.0053, oportunidade em que consignou que:

[...] as decisões administrativas devem ser analisadas também à luz dos princípios da razoabilidade e da proporcionalidade e, no caso específico com observância ao princípio da dignidade da pessoa humana, nos termos do artigo $1^{\circ}$, inciso III, da Constituição Federal. (Apelação $n^{\circ}$ 1043828-74.2017.8.26.0053, Relator Fermino Magnani Filho, 5a Câmara de Direito Público, julgado em 26/04/2018, grifo nosso).

De tudo o que consta da Constituição Federal de 1988, da Lei n 4.717/1965, da Doutrina e da Jurisprudência acima expostas e analisadas, os conceitos jurídicos indeterminadosinteresse público, prudência e discrição, carecem de uma atuação humana, qualificada por uma interpretação valorativa, que Ihes propicie uma definição Revista de Direitos Fundamentais \& Democracia, Curitiba, v. 25, n. 3, p. 209-231, set./dez. 2020 
jurídica alinhada às normas constitucionais e legais, para que possam orientar o operador do Direito nas suas decisões.

Nesse sentido, a Súmula 611 do STJ somente poderá ser considerada constitucional quando, a exemplo da jurisprudência firmada ao longo de anos nos Tribunais superiores, contemplar em seu texto que serão consideradas legais as investigações preliminares instauradas com base em denúncias anônimas, desde que instruídas com prudência e discrição, de forma a não ferir, desnecessariamente, os fundamentos da República Federativa do Brasil, bem como os direitos fundamentais dos cidadãos investigados.

\section{CONSIDERAÇÕES FINAIS}

Diante dos conceitos jurídicos indeterminados e da dificuldade interpretativa por eles criada, surge a exigência de que os órgãos aplicadores do direito, passem a adotar uma postura mais qualificada na construção do conteúdo semântico dos enunciados prescritivos sob sua análise, frente à impossibilidade da emissão de decisões a partir da simples subsunção de um fato da vida a um enunciado prescritivo previsto no direito positivo.

Portanto, é exigida do juiz ou da autoridade responsável pela aplicação do Direito ao caso concreto, uma postura altamente construtiva do conteúdo semântico dos enunciados prescritivos sob análise, do que uma atitude simplesmente declarativa, arraigada na subsunção do fato da vida ao enunciado prescritivo positivado. Trata-se da construção dos enunciados descritivos ou normas, que decorrem da atuação humana qualificada por uma interpretação que possibilite o preenchimento valorativo de que carecem os enunciados prescritivos, principalmente aqueles que contêm em sua estrutura conceitos jurídicos indeterminados.

Surge um espaço fértil à ocorrência do ativismo judicial, que se revela como um fenômeno pós-moderno caracterizado pela forte atuação do Poder Judiciário nas relações sociais, de forma a regular políticas públicas e intervir em aspectos da vida privada dos indivíduos.

Assim surgiu a Súmula 611 do STJ, de forma a permitir a instauração de investigações preliminares baseadas em denúncias anônimas, sem delimitar maiores contornos para a instrução de tais investigações, frente aos princípios da cidadania e da dignidade da pessoa humana, fundamentos da República Federativa do Brasil, sobre os quais se sustentam os direitos fundamentais da inviolabilidade da intimidade, 
da vida privada, da honra e da imagem das pessoas, conforme interpretação sistemática do contido no Art. $1^{\circ}$, incisos I e II c.c. o Art. $5^{\circ}$, inciso $\mathrm{X}$, todos da Constituição Federal de 1988.

Dessa forma, é com fundamento na Constituição Federal de 1988 , na Lei $n^{\circ}$ 4.717/1965, na Doutrina e na Jurisprudência acima exposta e analisada, que se afirma que a edição e a publicação da Súmula 611 do STJ revelam-se em um claro exemplo de ativismo judicial, pois ao limitar-se a reconhecer a legalidade da instauração de procedimentos investigativos a partir de denúncias anônimas, aquela Corte proferiu decisão subjetiva, vez que baseada no entendimento individualizado de seus membros, apartado do texto constitucional, da Lei, da Doutrina e da Jurisprudência, ou seja, baseou-se em entendimento afastado da vontade do povo, real detentor do Poder em um Estado Democrático de Direito.

Dessa forma, a Súmula 611 do STJ deve ser considerada inconstitucional, vez que, em seu texto, não observa os limites da prudência e da discrição como condições indispensáveis à relativização proporcional e razoável dos direitos fundamentais da vedação ao anonimato e da inviolabilidade da intimidade, da vida privada, da honra e da imagem, previstos no Art. $5^{\circ}$, incisos IV e X, respectivamente, da Constituição Federal brasileira, fulminando de morte a cidadania e a dignidade da pessoa humana, enquanto fundamentos da República Federativa do Brasil, conforme previsão contida no Art. $1^{\circ}$, incisos II e III, da Constituição Federal brasileira.

\section{REFERÊNCIAS}

ALEXY, Robert. Teoria dos Direitos Fundamentais. Tradução Virgílio Afonso da Silva. São Paulo: Malheiros, 2008.

BARROSO, Luis Roberto. Judicialização, Ativismo judicial e legitimidade democrática. [Syn]Thesis, Rio de Janeiro, v. 5, n. 1, p. 23-32, 2012.

Brasil. Decreto-Lei $\mathbf{n}^{0}$ 2.848, de 7 de dezembro de 1940. Código Penal. Disponível em:<https://www2.camara.leg.br/legin/fed/declei/1940-1949/decreto-lei-2848-7dezembro-1940-412868-publicacaooriginal-1-pe.html>. Acesso em: 22 mar.2019.

BRASIL. Lei $\mathbf{n}^{\circ}$ 4.717, de 29 de junho de 1965. Disponível em:

<http://www.planalto.gov.br/CCIVIL_03/LEIS/L4717.htm>. Acesso em: 18 fev. 2019.

BRASIL. Supremo Tribunal Federal. Súmula 473, SEÇÃO PLENÁRIA, julgado em 03/12/1969, DJ 10/12/1969, p.5945. Disponível em: < http://www.stf.jus.br/portal/jurisprudencia/listarJurisprudencia.asp?s1=473.NUME. $\% 20$ NAO\%20S.FLSV.\&base=baseSumulas>. Acesso em 18 fev. 2019. 
BRASIL. Constituição da República Federativa do Brasil de 1988, de 5 de outubro de 1988. Disponível em:

<http://www.planalto.gov.br/ccivil_03/Constituicao/Constituicao.htm>. Acesso em: 22 mar. 2019.

BRASIL. Superior Tribunal de Justiça. Recurso Ordinário em Habeas Corpus $\mathbf{n}^{\circ} 7.329$ - GO. Relator Ministro Fernando Gonçalves, julgado em 16 abr. 1998. Disponível em: <https://ww2.stj.jus.br/processo/ita/documento/mediado/?num_registro=199800127976 \&dt_publicacao=04-05-1998\&cod_tipo_documento= >. Acesso em: 22 mar. 2019.

BRASIL. Lei $\mathbf{n}^{\circ}$ 11.417, de 19 de dezembro de 2006. Regulamenta o art. 103-A da Constituição Federal e altera a Lei no 9.784, de 29 de janeiro de 1999, disciplinando a edição, a revisão e o cancelamento de enunciado de súmula vinculante pelo Supremo Tribunal Federal, e dá outras providências. Disponível em:

<http://www.planalto.gov.br/ccivil_03/_Ato2004-2006/2006/Lei/L11417.htm>. Acesso em: 22 mar. 2019.

BRASIL. Superior Tribunal de Justiça. Agravo Regimental no Recurso Especial 1307503/RR. Relator Ministro Mauro Campbell Marques, julgado em 06 ago. 2013. Disponível em:

<https://ww2.stj.jus.br/processo/revista/documento/mediado/?componente=ITA\&seque ncial=1250288\&num_registro $=201102954080 \&$ data $=20130813 \&$ formato=PDF $>$.

Acesso em: 22 mar. 2019.

BRASIL. Supremo Tribunal Federal. Recurso Ordinário em Habeas Corpus $\mathbf{n}^{\circ}$ 117.988 - RS. Relator Ministro Gilmar Mendes. Relator para o Acórdão Ministro Celso de Mello, julgado em 16 dez. 2014. Disponível em:

<http://redir.stf.jus.br/paginadorpub/paginador.jsp?docTP=TP\&docID=7865475>. Acesso em: 22 mar. 2019.

BRASIL. Tribunal de Justiça do Estado de São Paulo. Apelação no 1038853-

14.2014.8.26.0053. Relator Desembargador Maurício Fiorito, julgado em 19/05/2015. Disponível em:

<https://esaj.tjsp.jus.br/cjsg/getArquivo.do?conversationld=\&cdAcordao $=8468032 \&$ cdF oro=0\&uuidCaptcha=sajcaptcha_0bd42704392143c1857184feade7b1d8\&vICaptcha=f mjx\&novoVICaptcha=>. Acesso em: 19jun. 2019.

BRASIL. Tribunal de Justiça do Estado de São Paulo. Apelação n 1033670 -

62.2014.8.26.0053. Relator Desembargador Maurício Fiorito, julgado em 19/05/2015. Disponível em:

<https://esaj.tjsp.jus.br/cjsg/getArquivo.do?cdAcordao=9038942\&cdForo=0>. Acesso em: 19 jun. 2019.

BRASIL. Superior Tribunal de Justiça. Habeas Corpus n² 258.819 - SP. Relator Ministro Nefi Cordeiro, julgado em 19 abr. 2016. Disponível em:<https://ww2.stj.jus.br/processo/revista/documento/mediado/?componente=ITA\&se quencial $=1501983 \&$ num_registro $=201202353784 \&$ data $=20160429 \&$ formato=PDF $>$. Acesso em: 27 mar. $201 \overline{9}$.

BRASIL. Supremo Tribunal Federal. Agravo Regimental no Habeas Corpus ${ }^{\circ}$ 135.969 - MA. Relator Ministro Celso de Mello, julgado em 29 nov. 2016. Disponível 
em: <http://redir.stf.jus.br/paginadorpub/paginador.jsp?docTP=TP\&docID=12282329>. Acesso em: 27 mar. 2019.

BRASIL. Tribunal de Justiça do Estado de São Paulo. Apelação no 105108298.2017.8.26.0053. Relator Nogueira Diefenthaler, julgado em 04/05/2017. Disponível em: <https://esaj.tjsp.jus.br/cjsg/getArquivo.do?cdAcordao=11427292\&cdForo=0>. Acesso em: 19 jun. 2019.

BRASIL. Tribunal de Justiça do Estado de São Paulo. Apelação Cível n 100060646.2017.8.26.0024. Relator Desembargador Marcelo Semer, julgado em 13/11/2017. Disponível em: $<$ https://esaj.tjsp.jus.br/cjsg/getArquivo.do?cdAcordao=10970081\&cdForo=0>. Acesso em: 19jun. 2019.

BRASIL. Tribunal de Justiça do Estado de São Paulo. Apelação $\mathbf{n}^{0}$ 104382874.2017.8.26.0053. Relator Fermino Magnani Filho, julgado em 26/04/2018. Disponível em: <https://esaj.tjsp.jus.br/cjsg/getArquivo.do?cdAcordao=11405433\&cdForo=0>. Acesso em: 19jun. 2019.

BRASIL. Superior Tribunal de Justiça. Súmula 611, PRIMEIRA SEÇÃO, julgado em 09/05/2018, DJe 14/05/2018. Disponível em: <http://www.stj.jus.br/SCON/sumanot/toc.jsp?livre=(sumula\%20adj1\%20\%27611\%27). sub>. Acesso em 18 fev. 2019.

CANOTILHO, José Joaquim Gomes. Comentários à Constituição do Brasil. José J. Gomes Canotilho e outros (coords.). São Paulo: Saraiva, 2013.

CARMO, Valter Moura do; MESSIAS, Ewerton Ricardo. Pós-modernidade e principiologia jurídica: O ativismo judicial e sua validade no âmbito do Estado Democrático de Direito. Revista Brasileira de Direito, Passo Fundo, v. 13, n. 3, p. 189-205, set./dez., 2017. Disponível em:

<https://seer.imed.edu.br/index.php/revistadedireito/article/view/2163/1404>. Acesso em: 02 jan. 2019.

CARVALHO, Aurora Tomazini de. Teoria Geral Do Direito: O Constructivismo LógicoSemântico. 2009. 623 f. Tese (Doutorado em Mestrado) - Pontifícia Universidade Católica de São Paulo. São Paulo. 30 ago. 2009. Disponível em:

<http://www.dominiopublico.gov.br/download/teste/arqs/cp098895.pdf>. Acesso em: 22 mar. 2019.

CARVALHO, luri Mattos de. O princípio do interesse público sobre o privado: parâmetros para uma reconstrução. Revista Diálogo Jurídico, Salvador, n. 16, maio/ago. 2007. Disponível em: <http://www.direitopublico.com.br>. Acesso em: 27 mar. 2019.

CARVALHO, Paulo de Barros Algo sobre oConstructivismo lógico-semântico. São Paulo: Instituto Brasileiro de Estudos Tributários, 2014.

ENGISH, Karl. Introdução ao pensamento jurídico. Lisboa: Calouste Gulbenkian, 1988. 
FERRAZ JÚNIOR, Tércio Sampaio. Introdução ao estudo do direito. 5. ed. São Paulo: Atlas, 2007.

JUSTEN FILHO, Marçal. Curso de Direito Administrativo [livro eletrônico]. 4. ed. São Paulo: Revista dos Tribunais, 2016.

LIMA, Gabriel de Araújo. Teoria da supremacia do interesse público: crise contradições e incompatibilidade de seus fundamentos com a Constituição Federal. Revista de Direito Administrativo \& Constitucional, Belo Horizonte, ano 9, n. 36, p. 123-153, abr./jun. 2009. Disponível em:

<http://www.revistaaec.com/index.php/revistaaec/article/view/695/484>. Acesso em: 27 mar. 2019.

MEIRELLES, Hely Lopes. Direito Administrativo Brasileiro. 26. ed. São Paulo: Malheiros, 2001.

MELLO, Celso Antônio Bandeira de. Curso de direito administrativo. 30. ed. São Paulo: Malheiros, 2013.

MORCHÓN, Gregorio Robles. O Direito Como Texto: Quatro estudos se teoria comunicacional do direito. Barueri, SP: Manole. 2005.

NERY JÚNIOR, Nelson. Princípios do Processo Civil na Constituição Federal. 8. ed. São Paulo: Revista dos Tribunais, 2004.

RAMOS, Elival da Silva. Ativismo judicial: parâmetros dogmáticos. São Paulo: Saraiva, 2010.

SILVA, José Afonso da. Acesso à justiça e cidadania. Revista de Direito Administrativo, Rio de Janeiro, n. 216, p. 9-23, 1999.

STRECK, Lênio Luiz. Verdade e consenso. São Paulo: Saraiva, 2014.

VILANOVA, Lourival. Fundamentos do Estado de Direito. In: VILANOVA, Lourival Escritos Jurídicos e Filosóficos. v. I. São Paulo: IBET/Axis-Mundi, 2008.

Recebido em 26/06/2019 Aprovado em 11/11/2019 Received in 26/06/2019 Approved in 11/11/2019 